\title{
Melissa Ames and Sarah Burcon (2016). How Pop Culture Shapes the Stages of a Woman's Life. From Toddlers-In-Tiaras To Cougars-On-The Prowl. Basingstoke, Hampshire: Palgrave Macmillan. ISBN 9781137566171 (hardback)
}

\author{
Reviewed by Maricel Oró Piqueras*
}

How Pop Culture Shapes the Stages of a Woman's Life explores to what extent gender equality has still not been reached in different stages of a woman's life, despite reassurance from media that "we are living in a wonderland full of female success" (p. 1). This book draws on contemporary texts novels, films, TV series, self-help books, songs and musicals - popularised in the USA but are also widely read, watched and performed in other parts of the world. Ames and Burcon focus their analysis on stereotypical roles created and perpetuated in these expressions of popular culture, about girls and women from childhood to middle age and old age. These stereotypes paint a rosy and naïve picture of the life stages through which a woman undergoes, but they also send messages about women's socialisation and gender expectations, where age is a relevant marker in considering acceptable attitudes and choices. The book is divided into nine chapters, each tackling different stages that represent women's social development as they mature from children to older women. Thus, the authors write on childhood through adolescence in Chapter 2, moving towards stages that

* Maricel Oró Piqueras, Department of English and Linguistics, University of Lleida, Lleida, Spain 
International Journal of Ageing and Later Life

traditionally mark women's lives - such as dating, marriage and motherhood - in Chapters 3-7. Importantly, Chapters 8 and 9 focus on latemiddle age and old age, stages that have been usually overlooked in feminist criticism.

Within cultural gerontology, it is interesting to note the reference to some of the popularised stereotypes about women in later life such as "puma," "cougar" and "milf." These three terms refer to women in their late 40s, 50 s and 60s who, after having raised and taken care of a family in most cases, are portrayed as independent, self-assured, and proud of their bodies and sexuality. As the authors state in relation to other stereotypes in a woman's life, the cultural messages embedded in these terms are paradoxical. On the contrary, they are meant to empower older women. However, such empowerment is imbued through an emphasis on "oversexualisation" (p. 170) rather than on women's potential in the public space, either in their careers or their influence in politics or societal organisations. According to the authors, the animalistic and sexually charged terms within which these older women are recognised are opposed to the "Madonna" stereotype emphasised in popular fiction for girls and women, and instead placed within "the whore" stereotype, where a woman "has no desire for marriage or children but is rather out for her own sexual fulfilment" (p. 171). On the contrary, by analysing some of the popular texts in which these stereotypes were introduced and popularised, such as the film American Pie, the TV series How I Met Your Mother, or the more recently released Cougar Town, the authors argue that these stereotypes are usually used for a comic of humorous outcome, thus jeopardising the apparent empowerment of older women.

The authors argue that there is still a prevalent fear of ageing in Hollywood, which has a clear influence in real life. In the last chapter, which is focused on portrayals of the mature woman, the authors state the difficulties they had to find "films that depicted aging women's issues" such as "menopause, health, aging, or sexuality" (p. 207). Nevertheless, it is also acknowledged that there are more and more romantic comedies with actors and actresses in their 50s and 60s as protagonists, a tendency that Deborah Jermyn (2014) named "gerontocom" (p. 116). The impact of media's stereotypes on women, especially older women, has also become more discernible within social media. The authors conclude the chapter by 
How Pop Culture Shapes the Stages of a Woman's Life. Book review

using Hillary Clinton's presidential campaign as an example of the still underlying sexism and ageism against which a woman has to fight, especially when approaching their old age. The authors referred to a Twitter hashtag, \#HowOldIsHillary, in which users where encouraged to post comic pictures to illustrate Clinton's age.

All in all, Ames and Burcon's book represents breaking ground into the study of the cautionary tales and underlying expectations throughout a woman's life stages, with an emphasis on middle age, late middle age and old age, which have been neglected in women's studies until recently. The invisibility of the late middle-aged and older woman is evident not only in media but also within cultural and feminist criticism, as renowned cultural gerontologists such as Margaret Gullette $(1997,2004)$ and Kathleen Woodward (1999) have stated. With the use of contemporary and popular texts that are widespread, Ames and Burcon conclude that, despite a few advances in a more comprehensive portrayal of women's lives, the roles of wife, mother and grandmother - or in other words, the role of carer - are still prevalent as the "desired" stereotypes within popular culture, leaving little options for a woman once she reaches old age. As has been pointed out previously, the stereotypes and cultural messages referring to women throughout their life course direct them towards the accepted role of the "Madonna" rather than "the whore", with a prevalence of the role of the virtuous child who then becomes the perfect wife and mother and remains in her role as carer throughout her old age.

\section{References}

Gullette, M. M. (1997). Declining to Decline: Cultural Combat and the Politics of Midlife. Charlottesville: University of Virginia Press.

Gullette, M. M. (2004). Aged by Culture. Chicago: The University of Chicago Press.

Jermyn, D. (2014). The (Un-Botoxed) face of the Hollywood revolution: Meryl Streep and the greying of mainstream cinema. In I. Whelehand \& J. Gwynne (eds.), Ageing, Popular Culture and Contemporary Feminism. Harley and Hormones (pp. 109-120). London: Palgrave Macmillan.

Woodward, K. (ed.) (1999). Figuring Age. Women, Bodies, Generations. Bloomington, IL: Indiana University Press. 